\title{
Isometric Pull-Push Strengths in Workspace: 1. Strength Profiles
}

\author{
Biman Das \\ Department of Industrial Engineering, Dalhousie University, Halifax, NS, Canada \\ Yanqing Wang \\ School of Kinesiology, Simon Fraser University, Burnaby, BC, Canada
}

The isometric pull and push strength profiles of males and females were determined in seated and standing positions in the workspace. The strongest pull strength location was at extreme reach vertically above the shoulder for both males and females. The greatest pull strength of 400 Newtons (N) for males was recorded in the seated and standing positions. Females' pull strengths in the seated and standing positions were 222 and $244 \mathrm{~N}$, respectively. The strongest push strength was always at the maximum reach at the overhead location. Males' maximum push strength was $227 \mathrm{~N}$ in the seated position and $251 \mathrm{~N}$ in the standing position. Females' maximum push strength was $96 \mathrm{~N}$ in the seated position and $140 \mathrm{~N}$ in the standing position. On the average the strength in the standing position was $79 \%$ of the seated position. The push strength was $71 \%$ of the pull strength and females were $56 \%$ as strong as males.

isometric strength push and pull strengths workspace reach levels vertical and horizontal angles workstation design

\section{INTRODUCTION}

For designing work, equipment, workplaces, tools and controls, it is important to have the knowledge of what an operator can or cannot do under specified circumstances. The development of operator screening and job matching procedures based on human strengths are often recommended for manual materials handling activities. Thus the determination of human strength capabilities is necessary to develop engineering design guidelines and operator screening procedures. This will permit injury control in industry through the reduction of overloading of muscles $[1,2,3]$.

The determination of isometric or maximum static strength in the workspace is important because industrial workers should not generally exceed one third of their isometric strength on a sustained basis in task performance. Cumulative trauma disorders (CTD) may develop when excessive force is involved in a repetitive task with a cycle time shorter than 30 s [4]. Consequently it is important to determine isometric strength profiles in workspace for the optimum design of workstations. The ideal industrial workstation should be compatible not only with systems performance requirements but also with the user. The most obvious user criteria include work performance, safety and health [5].

For the creation of an ideal workstation, several factors must be considered, one of which is user reach capability. Accurate reach capability data are essential to ensure that all hand-operated controls or tasks are located where they can be reached and operated efficiently. For the upper body, this three-dimensional workspace has been divided into three contagious regions in order of increasing distance from the operator. These have been classified as normal, maximum and extreme reach envelopes. Normal workspace is closest to the body, being circumscribed by the horizontal

The research was supported by the Natural Sciences and Engineering Research Council (NSERC) of Canada.

Correspondence and requests for offprints should be sent to Biman Das, Department of Industrial Engineering, Dalhousie University, Sexton Campus, 5269 Morris St., PO Box 1000, Halifax, NS, B3J 2X4, Canada. E-mail: <Biman.Das@dal.ca>. 
lower arm pivoting about a relaxed vertical arm. Maximum workspace is circumscribed during movement of the fully extended arm about the shoulder. Extreme workspace is reached when movement of the trunk extends the reach of the fully extended arm without losing stability $[6,7,8,9]$.

In the creation of an ideal workstation, another factor that impinges is the user strength capability. For optimal workplace layout, it is imperative that the operator's strength profile be determined. The strength profile of an individual under specified conditions is essential for the design of tools (e.g., their weight, ease of use), controls (e.g., type of grip required, spatial placement), and equipment, in other words, the workstation. Furthermore, for the selection or job placement of workers requiring strength exertion in task performance, measurement of strength profiles of such individuals can be useful.

Past research has demonstrated objectively that the worker physiological cost was least when the task was performed within a normal reach envelope [10]. The worker's physiological cost during task performance increased significantly with the increase in the reach envelope from normal to maximum and from maximum to extreme. However, when force or strength is included in performing a task, normal reach may not be the optimal location for the task performance. Current research will demonstrate that the operator is able to exert more force in maximum and extreme reach envelopes. In a real life work situation, operators are required to perform tasks in normal, maximum and extreme reach envelopes. For designing an optimum workstation, it is important to determine the location(s) within the reach envelope, where the operator can exert greatest force. Conversely, it is also important to determine the location(s) within the reach envelope, where the operator is able to produce least amount of force or strength due to body or other constraints.

Human strength varies with many task-related factors including horizontal distance from the body, height, orientation of exertion and velocity
[11]. Research studies have shown that horizontal distance and vertical height of exertion significantly affect the force exertable both in static and dynamic strength tests $[12,13]$. However these studies have not attempted to relate anthropometric reach envelopes to the strength data obtained. Researchers have measured strength at varying elbow angles [14], fractions of the mean reach for the population $[13,15]$, or fixed distance [16]. Measurement locations have not been determined by individual functional reach regions. It is imperative that for optimum workstation design, a link must be established between an individual's ability to reach and exert force at functional reach regions. It is necessary to determine the locations in the reach envelope where force can be maximized for a given direction, so that the placement of the controls can be established optimally.

Industrial tasks are performed in a variety of orientations (standing or seating) and a variety of conditions. Lift exertions have often been studied in the past. Lift strength alone cannot be used to determine pull or push strength, as each of these varies differently with horizontal distance and vertical height [14]. Many industrial tasks require pulling and pushing of objects. Consequently push-pull radial exertions should be studied for optimum workstation design.

The comparison between sitting and standing postures provides some unique insight into the requirements of the tasks in the context of strength measurement. Yates and Karwowski [17] found that the loads lifted in standing positions were significantly greater than those in sitting positions. Acceptable weights for standing positions were 8 to $25 \%$ greater than those acceptable for sitting positions. Mital and Faard [16] concluded that isokinetic pull and push strength of males are almost $37 \%$ greater in the standing posture than in the sitting posture. Thus it is considered desirable to study the effect of standing and seating working positions on isometric pull and push strengths.

The National Institute of Occupational Safety and Health (NIOSH) [11] ascribed 20\% of 
overexertion injuries to pull-push activities and this can be extrapolated to represent $5 \%$ of all compensable work related injuries. Differences between pull and push exertions are characterized by their opposite exertion directions. Generally pull strength is acknowledged to be greater than push strength [13].

Women on average are approximately one third weaker than men [11], although the difference associated with gender depends on the body members involved in the exertion. Since gender affects strength significantly, both male and female should be studied in the determination of strength profile relative to the entire working population.

The main objective of this research was to determine the three-dimensional isometric pull-push strength profiles of male and female population of working age in standing and seated positions in normal, maximum and extreme workspace reach envelopes for workstation design optimization. Specifically, the experimental study measured how anthropometric reach distances, horizontal and vertical angles, working position and gender affect maximum voluntary isometric pull-push strength.

\section{METHOD}

The experimental method is presented under: participants (section 2.1.), strength measurement system (section 2.2.), experimental situation (section 2.3.), and experimental procedure (section 2.4.).

\subsection{Participants}

The participants studied consisted of 8 men and 8 women, university students of working age. All participants were screened in advance to ensure that none had a history of significant physical ailments or were currently on medication. The anthropometric characteristics of male and female participants are presented in Tables 1 and 2, respectively. The anthropometric characteristics are presented for each participant, in terms of age (years), weight $(\mathrm{kg})$, stature/height ( $\mathrm{mm})$, shoulder height ( $\mathrm{mm})$, elbow height $(\mathrm{mm})$, leg height $(\mathrm{mm})$, forearm-hand length $(\mathrm{mm})$ and shoulder length $(\mathrm{mm})$. The calculated range values had shown considerable variability in anthropometric characteristics among the participants (male and female), when compared to the mean values. For example, the male participants' anthropometric measurements were: age: 25 years (mean), 22-33 years (range); weight: 78 kg, 64-93 kg and stature/height: $1,775 \mathrm{~mm}, 1,710-1,820 \mathrm{~mm}$. The corresponding measurements of female participants were: age: 26 years, 20-39 years; weight: $61 \mathrm{~kg}$ and $51-80 \mathrm{~kg}$ and stature/height: $1679 \mathrm{~mm}, 1,600-1,800 \mathrm{~mm}$. Other anthropometric measurement had shown similar variability (Tables 1 and 2). The variability of anthropometric

TABLE 1. Anthropometric Characteristics of Male Participants

\begin{tabular}{|c|c|c|c|c|c|c|c|c|}
\hline Participant & $\begin{array}{c}\text { Age } \\
\text { (years) }\end{array}$ & $\begin{array}{c}\text { Weight } \\
\text { (kg) }\end{array}$ & $\begin{array}{c}\text { Stature/ } \\
\text { Height } \\
(\mathrm{mm})\end{array}$ & $\begin{array}{c}\text { Shoulder } \\
\text { Height } \\
(\mathrm{mm})\end{array}$ & $\begin{array}{c}\text { Elbow } \\
\text { Height } \\
(\mathrm{mm})\end{array}$ & $\begin{array}{l}\text { Leg } \\
\text { Height } \\
\text { (mm) }\end{array}$ & $\begin{array}{c}\text { Forearm } \\
\text {-Hand } \\
\text { Length } \\
(\mathrm{mm})\end{array}$ & $\begin{array}{c}\text { Shoulder } \\
\text { Length } \\
(\mathrm{mm})\end{array}$ \\
\hline 1 & 24 & 70 & 1,800 & 1,550 & 1,150 & 1,000 & 410 & 440 \\
\hline 2 & 33 & 90 & 1,810 & 1,530 & 1,140 & 950 & 400 & 430 \\
\hline 3 & 23 & 68 & 1,730 & 1,450 & 1,110 & 900 & 360 & 420 \\
\hline 4 & 24 & 76 & 1,820 & 1,500 & 1,140 & 990 & 390 & 470 \\
\hline 5 & 26 & 85 & 1,710 & 1,460 & 1,100 & 920 & 330 & 440 \\
\hline 6 & 22 & 64 & 1,800 & 1,540 & 1,150 & 1,060 & 390 & 440 \\
\hline 7 & 24 & 93 & 1,810 & 1,510 & 1,130 & 960 & 390 & 500 \\
\hline 8 & 25 & 79 & 1,720 & 1,430 & 1,060 & 870 & 355 & 460 \\
\hline$M$ & 25 & 78 & 1,775 & 1,496 & 1,123 & 956 & 378 & 450 \\
\hline Range & $22-33$ & 64-93 & 1,710-1,820 & $1,430-1,550$ & $1,060-1,150$ & $870-1,060$ & $330-410$ & $420-500$ \\
\hline
\end{tabular}


TABLE 2. Anthropometric Characteristics of Female Participants

\begin{tabular}{lcccccccc}
\hline & Age & Weight & $\begin{array}{c}\text { Stature } \\
\text { /Height } \\
\text { Participant }\end{array}$ & $\begin{array}{c}\text { Shoulder } \\
\text { Height } \\
\text { (years) }\end{array}$ & $\begin{array}{c}\text { Elbow } \\
\text { Height } \\
(\mathbf{m g})\end{array}$ & $\begin{array}{c}\text { Leg } \\
\text { Height } \\
(\mathbf{m m})\end{array}$ & $\begin{array}{c}\text { Forearm } \\
\text {-Hand } \\
\text { Length } \\
(\mathbf{m m})\end{array}$ & $\begin{array}{c}\text { Shoulder } \\
\text { Length } \\
(\mathbf{m m})\end{array}$ \\
\hline 1 & 22 & 56 & 1,600 & 1,300 & 1,000 & 820 & 310 & 400 \\
2 & 26 & 51 & 1,600 & 1,300 & 1,020 & 900 & 310 & 400 \\
3 & 39 & 57 & 1,600 & 1,300 & 980 & 810 & 310 & 400 \\
4 & 20 & 55 & 1,800 & 1,500 & 1,150 & 900 & 350 & 400 \\
5 & 28 & 52 & 1,710 & 1,420 & 1,080 & 990 & 320 & 370 \\
6 & 24 & 69 & 1,730 & 1,460 & 1,090 & 900 & 360 & 390 \\
7 & 24 & 66 & 1,700 & 1,400 & 1,100 & 950 & 380 & 390 \\
8 & 24 & 80 & 1,690 & 1,390 & 1,070 & 940 & 340 & 410 \\
$M$ & 26 & 61 & 1,679 & 1,384 & 1,061 & 901 & 395 & 450 \\
Range & $20-39$ & $51-80$ & $1,600-1,800$ & $1,300-1,500$ & $980-1,150$ & $810-990$ & $310-380$ & $370-410$ \\
\hline
\end{tabular}

characteristics among the participants is likely to have an impact on isometric pull-push strengths.

\subsection{Strength Measurement System}

Each measurement session was conducted using a specially designed computerized isometric strength measurement system (Figure 1 [18]). The details of the system are described elsewhere [18] with only the essentials of the system relevant to the present research highlighted here.

The measurement system consisted of eight components: (1) extended arm and handle, (2) force transducer, (3) supporting track, (4) rotating platform, (5) adjustable table, (6) adjustable chair, (7) stability sensors and (8) data collection system. The extendable arm was modified from a TAMA HC92 TITAN STILT Cymbal stand (Hoshino Gakki Manufacturing Co. Ltd., Japan) with ability to adjust over $1,000 \mathrm{~mm}$ in length and $90^{\circ}$ in angular direction. The force transducer (Durham Instruments MLP200 Mini Load Cell, Canada) was mounted with a bolt directly between the handle and the extendable column, calibrated for both compressive and tensile forces up to 4,316 Newtons (N). The entire arm was held with a supporting track (square tubing) which was fixed to a wall. The open section of the track allowed the arm to be mounted onto the tubing and clamped at any location. The extendable metal arm was mounted on a channel secured to the wall and ceiling to allow height variations while remaining stable throughout all exertion conditions. A lock gear at the interface of the channel and the extendible arm allowed angular changes of the arm. Thus, the force recording system was positioned for each test, locating the hand relative to the participant's arm at each reach. This ensured exertions along the hand-forearm axis for normal reach and hand-arm axis for maximum and extreme reach. The platform consisted of two levels: (1) the upper level controlled the horizontal angle by free rotation, and (2) the lower level supported the upper level and aligned the participants' shoulder pivot with the rotating center of the upper level. The table was used to simulate an individual's workstation for the seated working position. The table was adjustable in $25 \mathrm{~mm}$ increments forward and backward $325 \mathrm{~mm}$ and continuously vertically between 555 and $785 \mathrm{~mm}$ from the floor level. The table surface was always set at the elbow height of the participant. The chair was adjustable in height with the range of $400 \mathrm{~mm}$. Sensors consisted of two separate pieces of conductive aluminum tape, each attached by wires to a circuit which was closed as long as the two pieces touched. Sensors were placed underneath the chair legs and the buttocks for the seated position and the participants' feet for the standing position. Whenever one of the sensors was disconnected, an audile alarm was triggered. Body stability was monitored during the experimentation. The measurement data were 


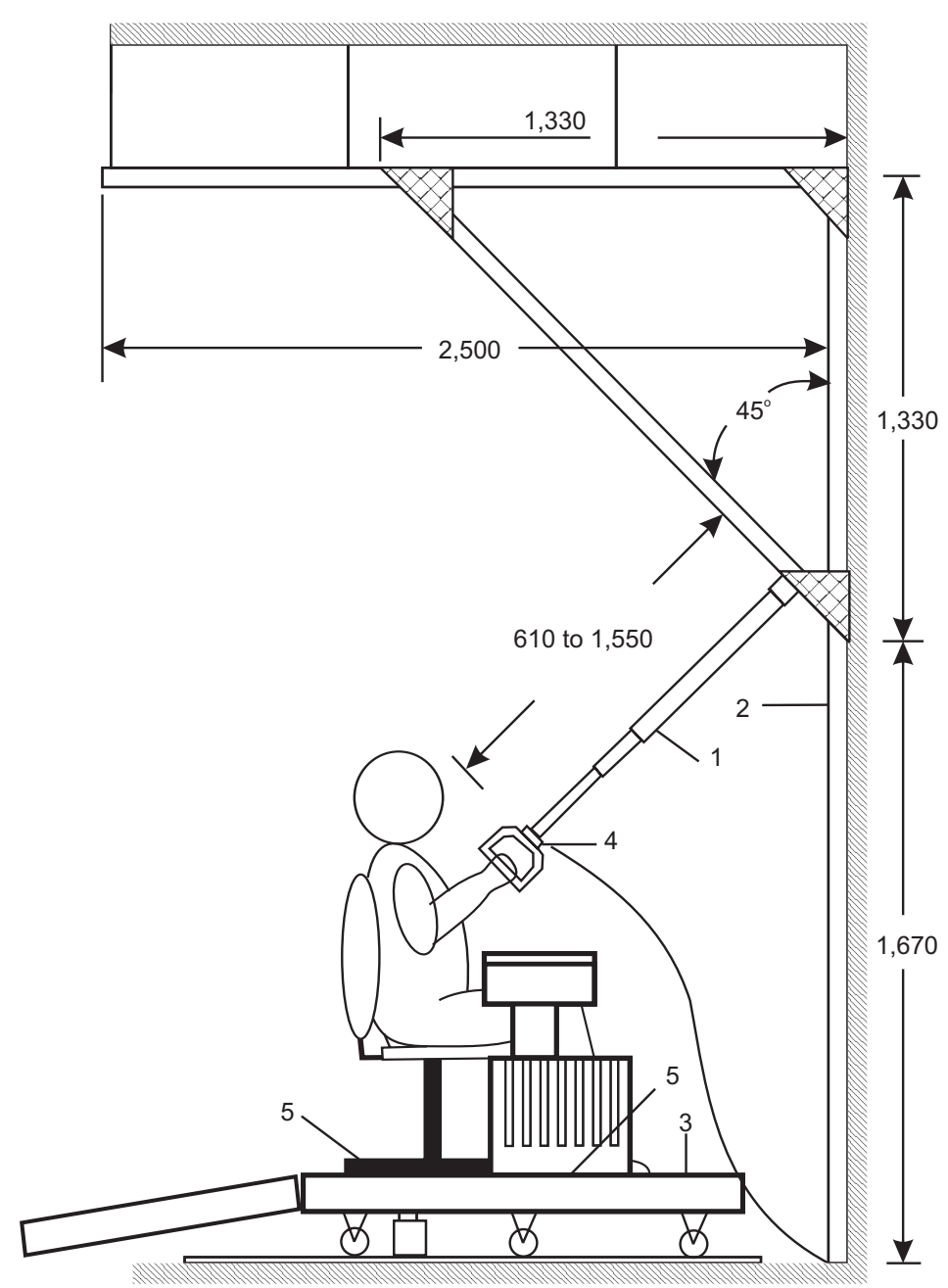

Figure 1. A computerized isometric strength measurements system. Notes. All dimensions in $\mathrm{mm}$. 1-extendable arm, 2-supporting track, 3-platform, 4-force transducer, 5—stability sensor.

collected and processed through a signal processor, analog/digital (A/D) converter and computer, located in a separated area, which had no spatial interaction with the simulated workstation.

The main advantage of the strength measurement system was its flexibility and adjustability. By adjusting the table or chair, it was possible to fit the participants with varying anthropometry, so that each participant had the same experimental condition. By adjusting the transducer arm or rotating platform, the system made it possible for the participant to exert isometric strength in any direction and location in workspace reach envelopes.

\subsection{Experimental Situation}

The independent variables in this experiment were:

(1) reach envelope at 3 levels: normal, maximum and extreme, (2) vertical angle $(\phi)$ at 3 levels: $0^{\circ}, 45^{\circ}$ and $90^{\circ}$ relative to the elbow height, (3) horizontal angle $(\theta)$ at 4 levels: $0^{\circ}, 45^{\circ}, 90^{\circ}$ and $135^{\circ}$ relative to the right side of the frontal plane, (4) force direction at 2 levels: pull and push, (5) working position at 2 levels: standing and sitting, and (6) gender at 2 levels: male and female. The dependent variable was the maximum isometric arm strength.

The individuals' functional reach levels were classified as normal, maximum and extreme reach envelopes. In this study, normal reach was defined as a space circumscribed by the forearm pivoting about a relaxed upper arm which moves out at the elbow height [7]. The maximum reach envelope was defined as being equal to the spatial volume confined by the motions made by the fully extended arm pivoting around the shoulder pivot point [6]. The extreme reach envelope was defined as a larger 
region extending beyond the maximum reach envelope, being only accessible with the movement of the trunk or torso that extend the reach of the fully extended arm without losing stability [9]. The movement of the trunk or torso allowed was approximately $15^{\circ}$ from the vertical plane, monitored by the experimenter. During the exercise, the participants were instructed not to actively use their left arm to either assist or stabilize themselves. No stabilizing device, such as a belt was used during strength measurement. Participants were only allowed to either let their left arm possibly hang or rest on the worktable. The overall posture was constantly monitored visually by the experimenter.

Three parameters were used to describe the isometric strength measurement locations: reach levels, vertical angles and horizontal angles. The vertical angle, $\phi=0^{\circ}$, was defined as the transverse plane at the elbow level, increasing clockwise when viewed from the left side of the body. The $\phi$ angle was set at the angles $0^{\circ}, 45^{\circ}$ and $90^{\circ}$ (Figures 2 and 3). The $\phi=90^{\circ}$ angle was in the overhead location but this was not accessible with the normal reach (Figure 2). The horizontal angle, $\theta=0^{\circ}$, was defined as the right side of the frontal plane, increasing counter-clockwise when viewed from the above. The measurements were recorded at $\theta$ angles of $45^{\circ}, 90^{\circ}$ and $135^{\circ}$ for normal reach (Figure 4 ) and $0^{\circ}, 45^{\circ}, 90^{\circ}$ and $135^{\circ}$ for maximum and extreme reach (Figure 5). There was no reach at $\theta=0^{\circ}$ (Figure 4). The isometric strengths were

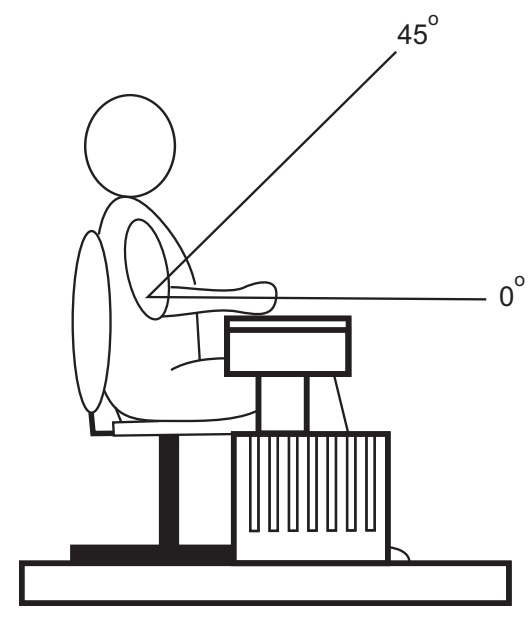

Figure 2. Locations for vertical angles for a normal reach envelope. measured at 24 locations which represented the individuals' workspace reach envelopes.

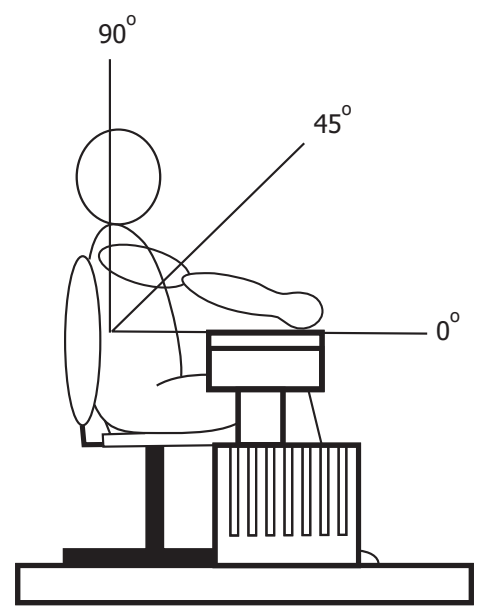

Figure 3. Locations for vertical angles for maximum and extreme reach envelopes.

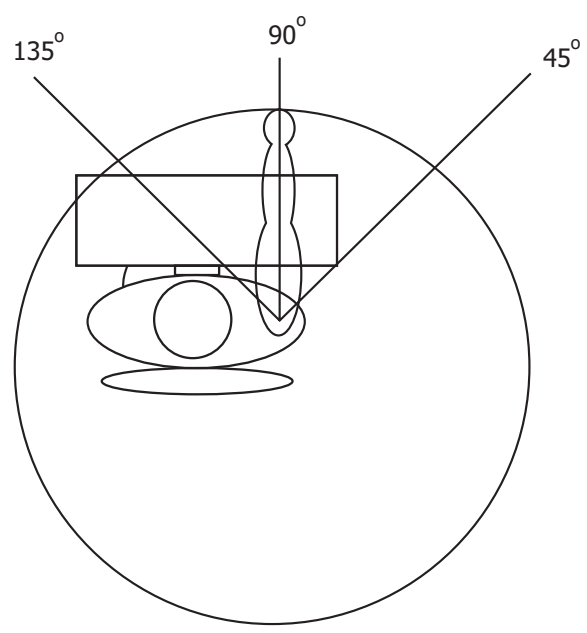

Figure 4. Locations of horizontal angles for a normal reach envelope.

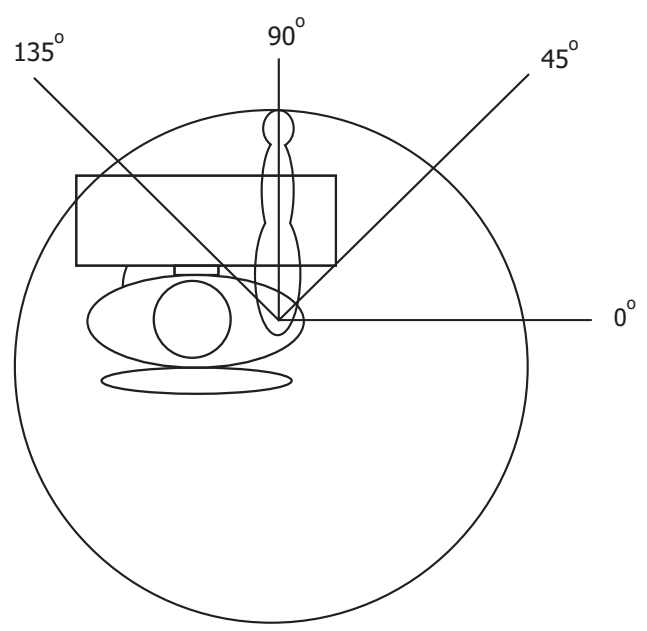

Figure 5. Locations of horizontal angles for maximum and extreme reach envelopes. 
In the standing position, feet were kept apart approximately equal to the shoulder-to-shoulder distance. In the seated position, the chair was adjusted to the proper height so as to ensure the knee angle at about $90^{\circ}$. The table surface was set at the elbow height with a clearance distance of about $2 \mathrm{~cm}$ in front of the body.

\subsection{Experimental Procedure}

The participant was instructed to maintain a slump posture during strength generation. The slump posture is defined for the purpose of this research as approximately $15^{\circ}$ forward from the vertical. The posture was visually monitored throughout the data collection. This allowed a relatively normal posture permitting realistic variations in posture anticipated in a work environment while imposing minimum controls for scientific validity.

The participants were asked to develop their maximum exertions as quickly as possible without jerking the hold until the end of a 5-s exertion period. At the end of each 5-s exertion period, a computer-generated graphic display of the test results was immediately outputted to a monitor. This allowed any trial with problem data to be discarded or repeated. A computer program was used to determine the final exertion/force output in Newtons (N). The sample values of the first $1.5 \mathrm{~s}$, the time to reach the maximum strengths were discarded. Also, the sample values of the last $0.5 \mathrm{~s}$ was discarded due to the possible muscle fatigue. The rest of the sample values of $3 \mathrm{~s}$ were averaged to determine the maximum isometric strength. Chaffin [19] has recommended exertion duration between 4 and $6 \mathrm{~s}$ with rest periods between $30 \mathrm{~s}$ and 2 min allowed between trials. A minimum of a 1-min rest period separated each exertion to ensure muscular fatigue recovery.

The strength measurement sessions for both the standing and the sitting positions took about $2 \mathrm{hrs}$ each for a total of about $4 \mathrm{hrs}$. At least a 1-day rest was given to the participants between tests for standing and sitting positions to avoid a fatigue effect. Also, a special strength measurement was made to determine fatigue, if any, involved in strength testing. At the beginning of strength testing, the participant was asked to pull and push at a point in front of the body with a posture that kept the elbow at an angle of $90^{\circ}$ with the upper arm in the neutral position. At the end of each measurement session (about $2 \mathrm{hrs}$ ), the participant was required to repeat the aforementioned procedure. This was done to determine the significant difference in strength output, if any, between the two (first and last) strength measurements. The statistical analysis showed that there was no systematic fatigue effect as a result of the strength measurements lasting about $2 \mathrm{hrs}$ in each experimental session. This also confirmed that a 1-min rest period between trials was adequate for muscular fatigue recovery. Caldwell et al. [20] had recommended a 2-min rest period between trials, however, this would obviously prolong the experimental session.

To control for stability, participants were not allowed to lean or grab onto any fixed object (including any portion of the chair) during exertions. Otherwise they were free to assume the posture they felt was most effective for force generation. This was necessary for normal variations in posture, which allowed each participant to exert maximum force or strength.

Radial pull and push exertions were measured for each of the 24 measurement locations defined by reach level (normal, maximum and extreme), vertical angle $(\phi)$ relative to the elbow (normal reach) or shoulder (maximum and extreme reach), and horizontal angle $(\theta)$ relative to the right shoulder in slump posture.

\section{RESULTS}

Experimental data were organized using an Excel computer program. Strength measurement data were broken down according to force direction, working position and gender: (1) pull strength of standing men, (2) pull strength of standing women, (3) pull strength of seated men, (4) pull strength of seated women, (5) push strength of standing men, (6) push strength of standing women, (7) push strength of seated men, and (8) push strength of seated women. The strength 
profiles in workspace reach envelopes (Tables 3-10) are presented in the context of workstation in the overhead location (Table 3). In the overhead location, in addition to arm muscles,

TABLE 3. Pull Strength (N) of Standing Men

\begin{tabular}{|c|c|c|c|c|c|c|c|}
\hline \multirow[b]{2}{*}{$\phi^{\circ}$} & \multirow[b]{2}{*}{$\theta^{\circ}$} & \multicolumn{2}{|c|}{ Normal Reach } & \multicolumn{2}{|c|}{ Maximum Reach } & \multicolumn{2}{|c|}{ Extreme Reach } \\
\hline & & $M$ & $S D$ & $M$ & $S D$ & $M$ & $S D$ \\
\hline 0 & 0 & - & - & 127.04 & 27.96 & 79.63 & 12.89 \\
\hline 0 & 45 & 126.38 & 30.15 & 124.67 & 16.52 & 81.13 & 25.48 \\
\hline 0 & 90 & 108.47 & 12.77 & 99.49 & 26.79 & 82.59 & 22.68 \\
\hline 0 & 135 & 114.55 & 11.84 & 111.69 & 24.88 & 75.06 & 16.23 \\
\hline 45 & 0 & - & - & 160.42 & 29.76 & 135.79 & 20.57 \\
\hline 45 & 45 & 170.19 & 32.41 & 166.21 & 26.72 & 135.14 & 23.56 \\
\hline 45 & 90 & 142.04 & 21.12 & 133.44 & 14.93 & 115.29 & 16.80 \\
\hline 45 & 135 & 159.52 & 23.11 & 159.37 & 24.79 & 136.93 & 24.92 \\
\hline 90 & 90 & - & - & 396.98 & 139.12 & 399.82 & 134.96 \\
\hline
\end{tabular}

Notes. Overall (average) strength $=147.58 \mathrm{~N}$.

design optimization. The isometric strength values are presented in terms of reach envelopes (normal, maximum and extreme), vertical angle $(\phi)$ and horizontal angle $(\theta)$. This will allow the designer of a workstation to place the controls in the appropriate workspace location to maximize strength capability. On the other hand, the designer will be able to avoid workplace location that will minimize strength capability.

\subsection{Pull Strength of Standing Men}

The strength values at extreme reach were consistently lower than those at normal and maximum reach with the exception of exertions shoulder muscles probably had contributed to generating the highest strength value.

\subsection{Pull Strength of Standing Women}

The strength values of standing women were lower at extreme reach in the horizontal plane $\left(\theta=0^{\circ}\right)$ than in other locations (Table 4).

Pull strength of standing men versus women. Women's average standing position was $58 \%$ of men's pull strength in the same position. There was no difference in pull strength patterns between standing men and women.

TABLE 4. Pull Strength (N) of Standing Women

\begin{tabular}{|c|c|c|c|c|c|c|c|}
\hline \multirow[b]{2}{*}{$\phi^{\circ}$} & \multirow[b]{2}{*}{$\theta^{\circ}$} & \multicolumn{2}{|c|}{ Normal Reach } & \multicolumn{2}{|c|}{ Maximum Reach } & \multicolumn{2}{|c|}{ Extreme Reach } \\
\hline & & $M$ & $S D$ & $M$ & $S D$ & $M$ & $S D$ \\
\hline 0 & 0 & - & - & 82.44 & 20.88 & 51.03 & 20.99 \\
\hline 0 & 45 & 74.47 & 27.18 & 79.05 & 22.97 & 58.89 & 28.77 \\
\hline 0 & 90 & 66.20 & 24.02 & 65.34 & 23.31 & 57.82 & 22.28 \\
\hline 0 & 135 & 72.25 & 28.38 & 66.88 & 20.83 & 58.35 & 14.95 \\
\hline 45 & 0 & - & - & 110.76 & 31.25 & 100.29 & 29.79 \\
\hline 45 & 45 & 89.42 & 37.89 & 100.96 & 33.03 & 93.10 & 26.72 \\
\hline 45 & 90 & 90.35 & 31.71 & 90.76 & 25.91 & 77.44 & 24.70 \\
\hline 45 & 135 & 87.68 & 30.53 & 83.72 & 21.39 & 89.31 & 23.69 \\
\hline 90 & 90 & - & - & 201.75 & 70.16 & 243.70 & 80.01 \\
\hline
\end{tabular}

Notes. Overall (average) strength $=85.09 \mathrm{~N}$. 


\subsection{Pull Strength of Seated Men}

The strength values at extreme reach were generally higher than those at normal and maximum reach (Table 5). This trend was contrary to the observations made for standing men.

Pull strength standing versus seated men. Men's pull strength in the standing position was lower that that in the seated position. The average strength value in the standing position was $65 \%$ of the corresponding value in the seated position. Thus a seated working position was more advantageous than a standing working position to achieve maximum pull strength output.

\subsection{Pull Strength of Seated Women}

The strength values of $\phi=45^{\circ}$ were consistently higher at extreme reach than at normal and maximum reach (Table 6).
Pull strength of seated men versus women.

Pull strength of seated women was $53 \%$ of seated men's pull strength.

Pull strength of standing versus seated women. Women in the standing position exerted $71 \%$ of the pull strength in the seated position.

\subsection{Push Strength of Standing Men}

The strength values at extreme reach were generally greater than those at normal or maximum reach with the exception of exertions in the overhead location (Table 7).

Pull versus push strength of standing men. Push strength of standing men was $83 \%$ of the pull strength in the same position.

Pull versus push strength of standing women. The average value of women's standing push

TABLE 5. Pull Strength (N) of Seated Men

\begin{tabular}{|c|c|c|c|c|c|c|c|}
\hline \multirow[b]{2}{*}{$\phi^{\circ}$} & \multirow[b]{2}{*}{$\theta^{\circ}$} & \multicolumn{2}{|c|}{ Normal Reach } & \multicolumn{2}{|c|}{ Maximum Reach } & \multicolumn{2}{|c|}{ Extreme Reach } \\
\hline & & $M$ & $S D$ & $M$ & $S D$ & $M$ & $S D$ \\
\hline 0 & 0 & - & - & 187.34 & 43.09 & 190.91 & 32.19 \\
\hline 0 & 45 & 187.58 & 37.64 & 217.89 & 54.95 & 238.61 & 56.64 \\
\hline 0 & 90 & 198.58 & 50.35 & 208.47 & 62.36 & 208.97 & 57.24 \\
\hline 0 & 135 & 188.13 & 33.31 & 174.50 & 41.25 & 187.05 & 43.26 \\
\hline 45 & 0 & - & - & 245.62 & 64.20 & 260.51 & 72.46 \\
\hline 45 & 45 & 244.80 & 66.67 & 264.21 & 69.27 & 256.32 & 59.32 \\
\hline 45 & 90 & 202.86 & 41.85 & 212.88 & 55.88 & 224.54 & 56.87 \\
\hline 45 & 135 & 217.48 & 50.37 & 217.96 & 70.23 & 222.28 & 47.72 \\
\hline 90 & 90 & - & - & 327.38 & 79.40 & 400.39 & 96.62 \\
\hline
\end{tabular}

TABLE 6. Pull Strength (N) of Seated Women

\begin{tabular}{|c|c|c|c|c|c|c|c|}
\hline \multirow[b]{2}{*}{$\phi^{\circ}$} & \multirow[b]{2}{*}{$\theta^{\circ}$} & \multicolumn{2}{|c|}{ Normal Reach } & \multicolumn{2}{|c|}{ Maximum Reach } & \multicolumn{2}{|c|}{ Extreme Reach } \\
\hline & & $M$ & $S D$ & $M$ & $S D$ & $M$ & $S D$ \\
\hline 0 & 0 & - & - & 95.69 & 35.32 & 107.02 & 47.73 \\
\hline 0 & 45 & 101.04 & 45.30 & 119.28 & 52.38 & 124.35 & 58.16 \\
\hline 0 & 90 & 106.84 & 52.53 & 115.50 & 62.72 & 102.33 & 50.26 \\
\hline 0 & 135 & 90.24 & 46.77 & 93.89 & 41.26 & 109.66 & 59.94 \\
\hline 45 & 0 & - & - & 115.50 & 49.95 & 151.84 & 66.64 \\
\hline 45 & 45 & 115.76 & 58.55 & 125.26 & 56.02 & 157.29 & 78.90 \\
\hline 45 & 90 & 113.54 & 56.89 & 119.71 & 55.27 & 126.31 & 47.55 \\
\hline 45 & 135 & 89.79 & 32.84 & 99.34 & 35.81 & 130.89 & 50.53 \\
\hline 90 & 90 & - & - & 158.95 & 55.85 & 221.92 & 101.74 \\
\hline
\end{tabular}

Notes. Overall (average) strength $=120.50 \mathrm{~N}$. 
TABLE 7. Push Strength (N) of Standing Men

\begin{tabular}{|c|c|c|c|c|c|c|c|}
\hline \multirow[b]{2}{*}{$\phi^{\circ}$} & \multirow[b]{2}{*}{$\theta^{\circ}$} & \multicolumn{2}{|c|}{ Normal Reach } & \multicolumn{2}{|c|}{ Maximum Reach } & \multicolumn{2}{|c|}{ Extreme Reach } \\
\hline & & $M$ & $S D$ & $M$ & $S D$ & $M$ & $S D$ \\
\hline 0 & 0 & - & - & 105.22 & 38.63 & 135.72 & 43.96 \\
\hline 0 & 45 & 106.01 & 28.19 & 94.54 & 33.85 & 125.68 & 25.64 \\
\hline 0 & 90 & 89.39 & 24.07 & 77.92 & 33.01 & 106.34 & 23.52 \\
\hline 0 & 135 & 99.85 & 30.38 & 75.87 & 26.46 & 124.83 & 22.05 \\
\hline 45 & 0 & - & - & 128.84 & 39.06 & 149.76 & 25.40 \\
\hline 45 & 45 & 135.15 & 29.77 & 107.34 & 44.56 & 160.35 & 44.59 \\
\hline 45 & 90 & 135.15 & 29.77 & 107.34 & 44.56 & 160.35 & 44.59 \\
\hline 45 & 135 & 131.60 & 29.62 & 79.08 & 20.09 & 138.70 & 22.64 \\
\hline 90 & 90 & - & - & 250.73 & 62.25 & 114.00 & 81.28 \\
\hline
\end{tabular}

Notes. Overall (average) strength $=122.63 \mathrm{~N}$.

strength was $99 \%$ of the pull strength of standing women.

\subsection{Push Strength of Standing Women}

Women's push strength profiles were similar to men's, nevertheless the absolute strength values of women were lower (Table 8).

Push strength of standing men versus women. Women's average push strength in the standing position was $69 \%$ of men's average push strength.

\subsection{Push Strength of Seated Men}

Except for the overhead location, the strength values were greater at extreme reach than at maximum reach (Table 9).
Push strength of standing versus seated men. Men's average push strength in the standing position was $88 \%$ of that in the seated position.

Pull versus push strength of seated men. Men's average push strength in the seated position was $61 \%$ of men's pull strength in the seated position.

\subsection{Push Strength of Seated Women}

Women's push strength profiles in the seated position showed some similarity with men's push strength profiles in the same position (Table 10). However, the strength values of women were much lower than those of men.

Push strength of seated men versus women. The average push strength of women in the

TABLE 8. Push Strength (N) of Standing Women

\begin{tabular}{|c|c|c|c|c|c|c|c|}
\hline \multirow[b]{2}{*}{$\phi^{\circ}$} & \multirow[b]{2}{*}{$\theta^{\circ}$} & \multicolumn{2}{|c|}{ Normal Reach } & \multicolumn{2}{|c|}{ Maximum Reach } & \multicolumn{2}{|c|}{ Extreme Reach } \\
\hline & & $M$ & $S D$ & $M$ & $S D$ & $M$ & $S D$ \\
\hline 0 & 0 & - & - & 65.84 & 17.93 & 107.64 & 42.47 \\
\hline 0 & 45 & 65.16 & 17.36 & 59.71 & 15.06 & 90.68 & 28.71 \\
\hline 0 & 90 & 660.22 & 18.48 & 48.49 & 15.27 & 78.11 & 24.02 \\
\hline 0 & 135 & 71.11 & 20.75 & 60.47 & 17.16 & 104.99 & 31.83 \\
\hline 45 & 0 & - & - & 78.02 & 24.62 & 100.01 & 25.69 \\
\hline 45 & 45 & 73.79 & 25.37 & 74.18 & 27.85 & 108.22 & 35.38 \\
\hline 45 & 90 & 87.00 & 26.29 & 65.10 & 29.19 & 116.26 & 43.95 \\
\hline 45 & 135 & 88.47 & 27.95 & 66.87 & 21.07 & 118.80 & 44.97 \\
\hline 90 & 90 & - & - & 139.56 & 33.66 & 99.38 & 28.35 \\
\hline
\end{tabular}

Notes. Overall (average) strength $=84.50 \mathrm{~N}$. 
TABLE 9. Push Strength (N) of Seated Men

\begin{tabular}{|c|c|c|c|c|c|c|c|}
\hline \multirow[b]{2}{*}{$\phi^{\circ}$} & \multirow[b]{2}{*}{$\theta^{\circ}$} & \multicolumn{2}{|c|}{ Normal Reach } & \multicolumn{2}{|c|}{ Maximum Reach } & \multicolumn{2}{|c|}{ Extreme Reach } \\
\hline & & $M$ & $S D$ & $M$ & $S D$ & $M$ & $S D$ \\
\hline 0 & 0 & - & - & 126.53 & 43.83 & 147.50 & 42.18 \\
\hline 0 & 45 & 136.58 & 47.25 & 139.59 & 36.59 & 158.68 & 42.84 \\
\hline 0 & 90 & 124.88 & 30.10 & 124.29 & 32.86 & 126.49 & 34.75 \\
\hline 0 & 135 & 125.10 & 29.69 & 104.84 & 30.73 & 111.49 & 31.11 \\
\hline 45 & 0 & - & - & 116.14 & 47.17 & 138.60 & 74.59 \\
\hline 45 & 45 & 132.02 & 47.12 & 136.73 & 62.05 & 147.76 & 49.95 \\
\hline 45 & 90 & 156.99 & 50.22 & 124.94 & 55.43 & 144.77 & 42.99 \\
\hline 45 & 135 & 162.97 & 72.72 & 118.53 & 50.59 & 135.91 & 44.14 \\
\hline 90 & 90 & - & - & 227.04 & 60.66 & 173.79 & 46.17 \\
\hline
\end{tabular}

Notes. Overall (average) strength $=139.26 \mathrm{~N}$.

TABLE 10. Push Strength (N) of Seated Women

\begin{tabular}{|c|c|c|c|c|c|c|c|}
\hline \multirow[b]{2}{*}{$\phi^{\circ}$} & \multirow[b]{2}{*}{$\theta^{\circ}$} & \multicolumn{2}{|c|}{ Normal Reach } & \multicolumn{2}{|c|}{ Maximum Reach } & \multicolumn{2}{|c|}{ Extreme Reach } \\
\hline & & $M$ & $S D$ & $M$ & $S D$ & $M$ & $S D$ \\
\hline 0 & 0 & - & - & 50.52 & 17.35 & 77.94 & 38.22 \\
\hline 0 & 45 & 64.09 & 27.46 & 62.16 & 29.22 & 74.57 & 42.60 \\
\hline 0 & 90 & 66.81 & 27.51 & 56.92 & 25.78 & 60.59 & 30.05 \\
\hline 0 & 135 & 61.53 & 28.64 & 47.39 & 20.77 & 59.81 & 24.90 \\
\hline 45 & 0 & - & - & 64.64 & 29.67 & 67.25 & 34.61 \\
\hline 45 & 45 & 38.27 & 24.38 & 75.98 & 35.41 & 74.18 & 32.61 \\
\hline 45 & 90 & 60.72 & 21.88 & 62.62 & 25.94 & 67.41 & 31.20 \\
\hline 45 & 135 & 73.68 & 26.62 & 59.09 & 21.97 & 72.15 & 29.84 \\
\hline 90 & 90 & - & - & 96.02 & 36.65 & 74.01 & 28.70 \\
\hline
\end{tabular}

Notes. Overall (average) strength $=66.60 \mathrm{~N}$.

seated position was $48 \%$ of men's average push strength in the same position.

Push strength of standing versus seated women. Women's average push strength in the standing position was $127 \%$ of that in the seated position.

Pull versus push strength of seated women. Women's push strength in the seated position was $55 \%$ of women's pull strength in that same position.

\section{DISCUSSION}

The implications of the research results involving able-bodied adult populations are discussed in the context of workstation design optimization.
Possible explanations are provided for the experimental results obtained in this study. A comparison is made between the results of this research with the available information and data found in the literature.

Limited research has been done in studying isometric pull-push profiles in the workspace. No study has been conducted that directly links an able-bodied person's strength profiles with their inherent normal, maximum and extreme reach profiles. So no direct comparison of the data given in this study with the data obtained elsewhere can be made. Several researchers, however, have used other factors such as degree of elbow flexion [16], fraction of mean reach for the population $[13,14]$ or fixed distances [15] to determine their effects on isometric arm strength. 
Rohmert [21] had measured right hand isometric pull-push strengths in the standing position at different percentages of maximum grip distances $(50,75$, and $100 \%)$ and at various arm angles $\left(60^{\circ}, 30^{\circ}, 0^{\circ},-30^{\circ}\right.$ and $\left.-60^{\circ}\right)$. Strengths were measured while the participants stood erect with feet parallel and $30 \mathrm{~cm}$ apart. The results had demonstrated the complexity of asymmetric exertions, with postures and force directions interacting to generate a large variation in strength values. If the left hand and the feet were allowed to assume different "bracing" configurations, the strength values generally would be expected to increase and to be more varied than the results obtained in the study [22]. Warwick et al. [23] had compared asymmetric pulling and pushing static strengths with different foot locations. The results revealed the extreme effect that posture and the direction of the force exerted can have on strength. Haselgrave et al. [24] showed that the strength values reported by both Rohmert [21] and Warwick [23] were about 30 to $50 \%$ lower than when one foot was allowed to shift freely to a bracing position. In an experimental study, Laubach [25] gave consideration to bracing a seated person to allow one-arm maximum pull and push exertions. In this experiment, aircraft seats were used with full shoulder and lap belts to brace the torso. The resulting static strengths were found to be greatly affected by the experimental condition.

Most of the past research focused on the effect of spatial factors on isometric strength. Hitherto three-dimensional isometric strength profiles in workspace were not developed for the purpose of optimizing workstation design. Of the past research studies, Hunsicker's [14] study of arm strength in relation to different degrees of elbow flexion comes closest to representing anthropometrically determined reach space envelopes. Hunsicker used 55 able-bodied males in his study.

The strongest pull strength of standing men occurred in the extreme overhead reach location. The superior performance in the overhead location was probably due to two reasons: (1) greater stability was achieved when exerting strength in the overhead location which kept the body in line with the direction of the force, and (2) back and leg muscles, in addition to the arm muscle had contributed to strength exertion in the overhead location for the standing position.

The pull strength values of seated women at $\phi=45^{\circ}$ were consistently higher at extreme reach than at normal or maximum reach. This was probably due to the use of body weight to gain additional strength output during pull exertions.

The push strength values of standing men at extreme reach were generally greater than those at normal or maximum reach with the exception of exertions in the overhead location. The greater push strength in the extreme reach envelope was probably achieved by leaning on the handle of the force transducer arm so as to take advantage of body weight.

Men's push strength in the standing position was found to be lower (88\%) than that in the seated position. This result was unexpected since previous studies $[16,17]$ indicated that strength performance in the standing position was generally greater than in the seated position. In the present study, the greater exertion stability in the seated position had probably played a decisive role in strength generation or output.

The pull and push exertions across the body $\left(\theta=135^{\circ}\right)$ were reduced significantly relative to angles on the same side of the active arm. Thus, generally tasks requiring pull or push strength should be located on the same side as the active arm. Similar work by Davis and Stubb [13] did not consider angles beyond $\theta=90^{\circ}$.

Vertical and horizontal angles played significant roles in determining strength potential. The greatest pulls occurred in front of the active arm $\left(\theta=90^{\circ}\right)$. Pull strength was consistently superior in the overhead aligned position $\left(\phi=90^{\circ}\right)$. It is notable that participants had consistently greater strength at heights above the shoulder, indicating the increased difficulty in pulling and pushing at levels with greater body extension. 
The role of reach level had a significant effect especially on the pulling strength of seated men and women. Pulling forces increased substantially with the increase in reach levels from normal to extreme, whereas pulling forces of standing men and women decreased substantially with the increase in reach levels. Consequently, a seated working position is advantageous for maximum pull strength output.

In designing work or task situations, preference should be given to tasks placed on the same side of the active limb where strength is required. Pulling tasks should be placed in front of the active shoulder where possible. Both pull and push values in the left side of the horizontal plane $\left(\phi=0^{\circ}\right.$ and $\left.\theta=135^{\circ}\right)$ tended to be lower than in other locations $\left(\theta=0^{\circ}, 45^{\circ}\right.$ and $\left.90^{\circ}\right)$ in reach envelopes. Consequently, strength performance in the left side of the body should be avoided. Davis and Stubbs [13] found the sagittal position $\left(\theta=90^{\circ}\right)$ to be best for strength performance. Biomechanically, the sagittal plane in front of the active shoulder corresponds to the most natural muscular strength for extensor and flexor muscles around the shoulder and this contributes to the superior strength at this location.

The overhead location was found to be the best place to achieve the greatest pull and push strength output for a short duration. However, for sustained exertions, working heights above heart level should be avoided to ensure workers' well-being. Considering the strength requirement and ergonomic principles, tasks should preferably be located at a vertical angle of $\phi=45^{\circ}$.

Push strength on average was $71 \%$ of pull strength. The greatest difference in strength due to the direction of the force occurred between push and pull strengths for seated women; push strength was only $55 \%$ of pull strength. The smallest difference was found between push and pull strengths of standing women; push strength was $93 \%$ of pull strength. Push strength of standing men was $83 \%$ of pull strength. Push strength of seated men was $61 \%$ of pull strength. Davis and Stubbs [13] acknowledged that pull strength is generally greater than push strength. Thus pulling action should be used in preference to pushing action whenever possible, especially in the seated working position.

The isometric strength in the seated position was greater than in the standing position (in all but one case). In men's pull strength, standing exertion was $65 \%$ as strong as seated exertion. Women's pull strength in the standing position was $71 \%$ of that in the seated position. Men's push strength in the standing position was $88 \%$ of that in the seated position. However, women's push strength in the standing position was $127 \%$ of that in the seated position. Based on the results, the seated position would be preferable to the standing position for men's pull and push and women's pull exertions. For women's push exertion, however, standing position would be better than the seated position. Yates and Karwowski [17] found in a lifting task situation that weights lifted for the standing position were 8 to $25 \%$ higher than those for the sitting positions.

The average women's strength was $56 \%$ of the men's strength. Women in comparison to men were 58 and $69 \%$ strong, in terms of standing pull and push strengths, respectively, whereas women compared to men were 53 and $48 \%$ strong in seated pull and push strengths, respectively. Thus, men were consistently stronger than women in strength exertions. Sale and Norman [26] found that upper body strengths between men and women differed by about $50 \%$, whereas Karwowski [27] reported average maximum strength capacity of male versus female as $69.9 \%$ with the range from 49.9 to $88.0 \%$.

\section{APPLICATION OF ISOMETRIC STRENGTH DATA FOR INDUSTRIAL WORKSTATION DESIGN}

Three-dimensional isometric pull and push strength data in workspace reach envelopes developed in this research can be used advantageously for industrial workstation design. 
The data are presented (Tables 1-8) in terms of spatial factors: reach levels (normal, maximum and extreme), vertical $(\phi)$ angles $\left(0^{\circ}, 45^{\circ}, 90^{\circ}\right)$, horizontal $\theta$ angles $\left(0^{\circ}, 45^{\circ}, 90^{\circ}\right.$ and $\left.135^{\circ}\right)$ for the seating and standing working positions for both the male and female populations. An appropriate methodology is needed for the application of isometric pull and push strength data for industrial workstation design. The methodology is explained by means of an example.

Let us suppose it is desired to find the optimum isometric pull strength in the seated working position in the maximum reach envelope for operating a control object or equipment on a sustained or continuous basis where both men and women are involved. It is desirable from an ergonomics viewpoint to obtain pull strength value for the 5 th percentile females, since both men and women are involved. Table 4 gives the pull strength values in Newtons (N) of seated women. Since the task will be performed on a sustained basis, the optimum pull strength mean value $(\bar{x})$ is $125.26 \mathrm{~N}$ and standard deviation $(S D)$ is $56.02 \mathrm{~N}$ at $\phi=45^{\circ}$ and $\theta=$ $45^{\circ}$ (Table 4). The maximum pull strength mean value of $158.95 \mathrm{~N}$ and standard deviation of $55.85 \mathrm{~N}$ will not be used on a sustained basis, because at $\phi=90^{\circ}$ and $\theta=$ $90^{\circ}$ will require performance in the overhead location (above heart level), suitable only for a short duration. The maximum pull strength for the 5th percentile female can be determined by using the formula: $\bar{x}-1.645 S D=125.26-1.645 \times 56.02=34.11 \mathrm{~N}$. However for performing tasks on a sustained or continuous basis only one third of the maximum isometric strength value should be used [4]. Consequently, the optimum pull strength value will be $1 / 3 \times 34.11=11.37 \mathrm{~N}$ in the maximum reach envelope at $\phi=45^{\circ}$ and $\theta=45^{\circ}$. However, for operating a control object or equipment on an intermittent basis, in a similar work situation, the optimum pull strength value will be $34.11 \mathrm{~N}$.

Based on the methodology presented here, it will be also possible to determine the optimum strength value for a predetermined location, identified with a vertical angle $(\phi)$, horizontal angle $(\theta)$ and reach level (normal, maximum and extreme). Since spatial parameters are discrete values, interpolation may be necessary to accommodate other values for horizontal and vertical angles. However, caution is required for such interpolations.

It should be recognized that in this study, the strength measurement values were obtained through the use of a $2.5 \mathrm{~cm}$ diameter handle, which allowed a comfortable cylinder grip. However, the use of different types of grips and handles can have a significant effect on strength measurement values.

\section{LIMITATION OF THE RESEARCH}

The limitation of this research especially the small sample size should be recognized. In this research only 8 male and female (able-bodied) participants were used and they were of working age that ranged from 20 to 39 years. For the purpose of this study, the sample size was considered adequate for determining strength profiles in terms of means and standard deviations and performing subsequent statistical analyses: analysis of variance or ANOVA and Fishers' pair-wise comparison test (presented in the following paper on the subject, Isometric Pull-Push Strengths in Workspace: 2. Analysis of Spatial Factors). Based on this (pilot) study, a comprehensive (isometric push, pull, push-up and pull-down strengths) future study was proposed involving a larger sample size of able-bodied populations (male and female).

\section{CONCLUSIONS}

In summary, the conclusions reached from this investigation are as follows.

1. The greatest pulling strength was at extreme reach in all cases at $\phi=90^{\circ}$ and $\theta=90^{\circ}$. Men's strongest pull strength of $400 \mathrm{~N}$ was realized in the seated position, equal to that in the standing position. Women's maximum pull strength values in the standing and seating positions were 244 and $222 \mathrm{~N}$, respectively. 
2. The greatest pushing strength occurred in the maximum reach envelope in the overhead location at $\phi=90^{\circ}$ and $\theta=90^{\circ}$. Men's maximum push strength values in the standing and seated positions were 251 and $227 \mathrm{~N}$, respectively. Women's maximum push strength of $140 \mathrm{~N}$ occurred in the standing position and $96 \mathrm{~N}$ in the seated position.

3. In a normal reach envelope, the greatest pull or push strength always took place at $\phi=45^{\circ}$. Maximum pull strength in a normal reach envelope was $245 \mathrm{~N}$ for men in the seated position at $\phi=45^{\circ}$ and $\theta=45^{\circ}$, whereas maximum push strength in a normal reach envelope was $163 \mathrm{~N}$ for men in the seated position at $\phi=45^{\circ}$ and $\theta=135^{\circ}$. Women's maximum strength in a normal reach envelope was $116 \mathrm{~N}$ at $\phi=45^{\circ}$ and $\theta=45^{\circ}$, when pulling in the seated position.

4. Both pull and push values in the left side of the horizontal plane $\left(\phi=0^{\circ}\right.$ and $\left.\theta=135^{\circ}\right)$ tended to be lower than other locations in reach envelopes.

5. On average push strength was $71 \%$ of pull strength. Thus pulling actions should be preferred to pushing actions whenever possible.

6. In general, pull and push strengths in the seated position were greater than in the standing position. There was one exception in that women's push strength was lower in the seated position than in the standing position.

7. The average women's strength was $56 \%$ of men's strength.

8. A methodology was developed for the application of isometric pull and push strength data for industrial workstation design.

\section{CONCLUDING REMARKS}

For an optimum design of workstation, it is necessary to determine the locations(s) within the various reach envelopes, where operators can exert greater as well as lower force or strength for task performance. The investigation has provided isometric pull and push strength data and a methodology for the application of the data to facilitate optimization of workstation design. The measurement of an individual's isometric strength can be very useful for job placement purposes to meet the requirement of current strength of work demands. However, it should recognized that data were obtained from a limited sample size.

The three-dimensional strength profiles for males and females using radial pull and push exertions show significant differences in absolute value as well as spatial locations. The experimental results clearly show the importance of strength capabilities in the design and placement of controls in the work area.

\section{REFERENCES}

1. Chaffin DB, Herrin GD, Keyserling WM. Pre-employment strength testing-an updated position. J Occup Med 1978;20: 403-9.

2. Kyserling WM, Herrin GD, Chaffin DB. Isometric strength testing as a means of controlling medical incidents on strenuous jobs. J Occup Med 1980;22:232-336.

3. Mital A, Das B. Human strength and occupational safety. Clin Biomech 1987;2: 97-106.

4. Putz-Anderson V, editor. Cumulative trauma disorders: a manual for musculosketetal diseases of the upper limbs. London, UK: Taylor \& Francis; 1994.

5. Das B, Sengupta AK. Industrial workstation design: a systematic ergonomics approach. Appl Ergon 1996;27(3):157-63.

6. Farley RR. Some principles of methods and motion study as used in development work. General Motors Engineering Journal 1955;D2-90549:1-46.

7. Squires PC. The shape of the normal working area (Report No. 275). New London, CT, USA: U.S. Navy Department 
Bureau of Medicine and Surgery, Medical Research Laboratories; 1956.

8. Das B, Behara DN. Determination of normal horizontal working area: a new model and method. Ergonomics 1995;38(4):734-48.

9. Sengupta AK. Anthropometric modeling and evaluation of workspace for industrial workstation design [doctoral dissertation]. Halifax, NS, Canada: Department of Industrial Engineering, Technical University of Nova Scotia; 1995.

10. Sengupta AK, Das B. Determination of worker physiological cost in workspace reach envelopes. Ergonomics. In press.

11. National Institute of Occupational Safety and Health (NIOSH). Work practices guide for manual lifting. Cincinnati, OH, USA: U.S. Department of Health and Human Services; 1981.

12. Chaffin DB, Park KS. A longitudinal study of low-back pain as associated with occupational weight lifting factors. Am Ind Hyg Assoc J 1973;34:513-25.

13. Davis PR, Stubbs DA. Safe levels of manual forces for young males (1). Appl Ergon 1977; 8(3);141-50.

14. Hunsicker PA. Arm strength at selected degrees of elbow flexion (WADC Technical Report No. 54-548). Wright-Patterson AFB, OH, USA: Wright Air Development Centre (WADC); 1955.

15. Kumar S. Arm lift strength in work space. Appl Ergon 1991;22:317-28.

16. Mital A, Faard H. Effects of sitting and standing, reach distance and arm orientation on isokinetic pull strengths in the horizontal plane. Int J Ind Ergon 1990;6:241-8.

17. Yates JW, Karwowski W. Maximum acceptable lifting loads during seated and standing position. Appl Ergon 1987;18(3): 239-43.

18. Black N. Isometric strength in the workspace reach envelopes of paraplegics
[Master of Applied Science thesis]. Halifax, NS, Canada: Department of Industrial Engineering, Technical University of Nova Scotia; 1994.

19. Chaffin DB. Ergonomics guide to the assessment of human static strength. Am Ind Hyg Assoc J 1975;36:505-11.

20. Caldwell LS, Chaffin DB, Duke-Dobos FN, Kroemer KHE, Laubach LL, Snook SH, et al. A proposed standard procedure for static muscle strength testing. Am Ind Hyg Assoc J 1974;35:201-6.

21. Rohmert W. Maximalkrafte von Männern im Bewegungsraum der Arme und Beine. Köln, Germany: Westerdeutscher Verlag; 1966.

22. Chaffin DB, Andersson GBJ, Martin BJ. Occupational biomechanics. 3rd ed. New York, NY, USA: Wiley; 1999.

23. Warwick D, Nowak G, Schultz A. Maximum voluntary strengths of male adults in some lifting, pushing and pulling activities. Ergonomics 1980;23(1):49-54.

24. Haselgrave CM, Tracy MF, Corlett EN. Force exertion in awkward working postures - strength capability while twisting or working overhead. Ergonomics 1997;40(12):1335-62.

25. Laubach LL. Human muscular strength. In: Webb Associates, editors. Anthropometric source book (NASA Reference Publication 1024). Washington, DC, USA: National Aeronautics and Space Administration (NASA); 1978. p. 1-55.

26. Sale DG, Norman RW. Testing strength and power. In: MacDougall JD, Wenger HA, Green HJ, editors. Physiological testing of the elite athlete. Ithaca, NY, USA: Movement Publications; 1982. p. 7-37.

27. Karwowski W. Maximum load lifting capacity of males and females in teamwork. In: Proceedings of the Human Factors Society 32nd Annual Meeting. Santa Monica, CA: Human Factors Society; 1988. p. $680-2$. 